\title{
O CRIME DE DESERÇÃO E SUA RECEPÇÃO PELA CONSTITUIÇÃO FEDERAL DE 1988: OS CONTORNOS LEGAIS E DOUTRINÁRIOS DOS CRIMES DE DESERÇÃO SIMPLES E ESPECIAL E A ANÁLISE DE COMPATIBILIDADE ENTRE OS ARTIGOS 187 E 190 DO CÓDIGO PENAL MILITAR E A CONSTITUIÇÃO
}

\section{ARTIGO ORIGINAL}

COELHO, Everton Paul Matheus ${ }^{1}$, GARCIA, Maria ${ }^{2}$

COELHO, Everton Paul Matheus. GARCIA, Maria. O crime de deserção e sua recepção pela constituição federal de 1988: os contornos legais e doutrinários dos crimes de deserção simples e especial e a análise de compatibilidade entre os artigos 187 e 190 do código penal militar e a constituição. Revista Científica Multidisciplinar Núcleo do Conhecimento. Ano 06, Ed. 09, Vol. 02, pp. 98-122.

Setembro de 2021. ISSN: 2448-0959, Link de acesso:

https://www.nucleodoconhecimento.com.br/administracao/constituicaofederal

\section{RESUMO}

O presente artigo científico tem como objetivo analisar dois institutos jurídicos contidos no Código Penal Militar brasileiro (Decreto-Lei o 1001, de 21 de outubro de 1969), quais sejam: o crime de deserção simples (artigo 187) e o crime de deserção especial

\footnotetext{
${ }^{1}$ Mestrando em Direito Constitucional pela Pontifícia Universidade Católica de São Paulo (PUC/SP), pós-graduado em Direito Administrativo, Constitucional e Militar pela Faculdade Venda Nova do Imigrante (FAVENI), graduado no curso de Direito pela Faculdade de Direito de São Bernardo do Campo (FDSBC). ORCID: https://orcid.org/0000-0001-5949-9916
}

2 Orientadora.

RC: 96606

Disponível em: https://www.nucleodoconhecimento.com.br/administracao/constituicao-federal 
(art. 190). O legislador infraconstitucional previu no ordenamento jurídico esses

dispositivos repressivos com o objetivo de tutelar a devida prestação do serviço militar que resta prejudicada por aqueles militares que se mantém ilegalmente ausentes frente a esse dever. A investigação desta pesquisa foi realizada por meio da revisão legal dos dispositivos e das obras doutrinárias que abordam o tema. Para nortear a pesquisa, foram consideradas as seguintes questões principais: a) qual a principal diferença entre a deserção simples prevista no artigo 187 do Código Penal Militar e a deserção especial compreendida no artigo 190 do mesmo diploma legal? b) o Código Penal Militar prevê mais de duas modalidades do crime de deserção? c) os referidos dispositivos legais que tratam sobre o crime de deserção foram recepcionados pela Constituição Federal de 1988? Concluímos que a principal diferença entre a deserção simples e a especial encontra-se na forma de consumação do crime, enquanto na primeira é necessário o decurso do "prazo de graça", oito dias a contar da ausência ilegal do militar, a segunda modalidade, também chamada de deserção instantânea não necessita do decurso do "prazo de graça". Também foi verificado que o Código Penal Militar prevê três modalidades do crime de deserção, não apenas duas, sendo elas: a deserção simples (art. 187), a deserção denominada de "casos assimilados" ou ainda "formas assemelhadas", que trazem quatro hipóteses de incidência criminal (art. 188) e a deserção especial (art. 190), bem como verifica-se que os referidos dispositivos legais que tratam sobre o crime de deserção foram recepcionados pela Constituição Federal de 1988, tendo-se em vista que a sua materialidade não se encontra em desacordo com o texto constitucional, segundo a doutrina e a jurisprudência.

Palavras-chaves: Contornos legais e doutrinários, Crime de deserção, Artigos 187 e 190 do Código Penal Militar, Recepção pela Constituição Federal de 1988. 


\section{INTRODUÇÃO}

O presente trabalho tem como objeto de estudo o crime de deserção, previsto no Código Penal Militar brasileiro (Decreto-Lei no 1001, de 21 de outubro de 1969) nos artigos 187 a 194, bem como 391 a 393, concentrando-se, pois na análise entre a modalidade de deserção simples (art. 187) e a modalidade de deserção especial (art. 190) e se tais dispositivos legais foram recepcionados pela Carta Magna vigente.

O tema abordado na pesquisa é a análise minuciosa sobre essas modalidades do crime de deserção e sua interpretação doutrinária como um todo, sendo este tema de especial importância para o ordenamento jurídico militar, pois versa sobre o empenho das instituições militares em dispor de seu efetivo, íntegro e capaz, no objetivo de cumprir com suas missões de garantia do cumprimento da lei, a preservação da soberania nacional, do patrimônio público e da integridade territorial nacional, dentre outras atribuições constitucionais.

Tamanha é a importância do tema que Siqueira (2011, p. 23) aponta que o valor mais importante no Código Penal Militar é a Pátria, e nota que esse valor se reflete no posicionamento topográfico do crime de deserção, que antecede até mesmo o crime de homicídio. Esse é apenas mais um elemento que demonstra a importância dada à Pátria pelo legislador e como a decisão de criminalizar a conduta da deserção está atrelada a garantia da segurança nacional.

O objetivo da pesquisa é examinar os contornos legais e doutrinários que envolvem o crime de deserção e suas modalidades de maneira analítica e sistemática.

A metodologia utilizada para atingir o objetivo é a revisão legal e doutrinária desse instituto penal que é o crime de deserção, percorrendo as disposições do Código Penal Militar, e os principais autores sobre o assunto, delineando assim os limites do crime em análise. 
Para direcionar a pesquisa foram selecionadas as seguintes perguntas a serem respondidas em conclusão, após a análise completa através da metodologia: a) qual a principal diferença entre a deserção simples prevista no artigo 187 do Código Penal Militar e a deserção especial compreendida no artigo 190 do mesmo diploma legal? b) as penas imposta pela lei para ambos os crimes têm a mesma densidade repressiva? c) o Código Penal Militar prevê mais de duas modalidades do crime de deserção? d) as disposições legais que tratam sobre o crime de deserção foram recepcionadas pela Constituição Federal de 1988?

No primeiro item do trabalho são expostas considerações gerais sobre o crime de deserção na legislação penal militar brasileira; e nos subitens 1.1 e 1.2 estão as, respectivas, análises da objetividade jurídica do crime de deserção e os sujeitos envolvidos no delito.

Nos itens 1.4 e 1.5 estão expostos os elementos objetivos e subjetivos do tipo penal e ao final do primeiro capítulo, nos itens 1.5 e 1.6 temos a análise de como ocorre a consumação do crime, as considerações acerca da possibilidade de configuração desse crime na forma tentada e a classificação doutrinária do crime.

No capítulo dois são exploradas as questões atinentes ao fenômeno da recepção constitucional. Tal análise é relevante tendo-se em vista que a legislação penal militar objeto de estudo é anterior à promulgação da atual Constituição e nesta esteira há questionamentos se os dispositivos legais do diploma castrense se coadunam com os princípios e disposições constitucionais vigentes.

Com base no exposto, o desenvolvimento do artigo seguiu o método dedutivo combinado com o método dialético tomando por base a pesquisa bibliográfica referenciada por meio de livros, artigos, periódicos e a jurisprudência do Supremo Tribunal Federal sobre o tema proposto. 


\section{CRIME DE DESERÇÃO NA LEGISLAÇÃO PENAL MILITAR BRASILEIRA}

A deserção é um dos crimes mais tradicionais e com maior relevância na legislação militar. Nas palavras de Crysólito de Gusmão a deserção consiste no "acto do militar que rompe o laço que o liga á milícia, affastando-se, dentro de certas circunstâncias de tempo, da bandeira" (GUSMÃO, 1915, p. 97).

Cometer este delito é gravíssimo, pois atinge, diretamente, um dos alicerces que sustentam as instituições militares: o princípio da disciplina.

O princípio da disciplina detém valor ímpar no Código Penal Militar (CPM), haja vista sua essencialidade para a manutenção da eficiência e da capacidade das forças armadas em manter seu efetivo íntegro, apto e disponível a promover a segurança da Pátria.

O critério adotado pelo legislador, ao situar as disposições desse crime no CPM, demonstra sua essencialidade e materializa o que podemos descrever como uma maior autoridade, uma supremacia do valor atribuído ao bem jurídico resguardado pelo tipo penal da deserção, até mesmo em relação ao valor da vida. Nesse sentido Siqueira (2011, p. 23) aponta:

Tais valores, no citado Estatuto Repressivo Castrense, topograficamente, antecedem ao delito do homicídio. O crime de deserção se encontra encartado no Título III, ao passo que o de homicídio no Título IV. O CPM tutela a função militar, eis que as Forças Armadas estão comprometidas com a Defesa da Pátria. A vida é o valor mais importante no CP (art. 121, Título I). A pátria é o valor mais importante no CPM.

Avançando em relação à previsão da deserção na Legislação Penal Militar, temos os artigos 187, 188, 189, 190, 191, 192, 193, 194, 391, 392 e 393, todos do Código Penal Militar e os artigos 451, 452, 453, 454, 455, 456, 457, esses, todos do Código de Processo Penal Militar. Todos esses artigos de lei guardam relação direta com o crime

RC: 96606

Disponível em: https://www.nucleodoconhecimento.com.br/administracao/constituicao-federal 
de deserção, entretanto não analisaremos todos, tendo em vista a necessidade de nos concentrarmos apenas nas principais modalidades de deserção. Aliás, o CPM abrange três modalidades de deserção.

Quanto às modalidades da deserção, nos ensina Lobão (1999, p. 69):

Três são as modalidades da deserção contempladas no diploma repressivo castrense. $\mathrm{Na}$ primeira, a conduta incriminada é ausentarse, sem autorização, da unidade ou do lugar onde serve, passando o militar, desde logo, à condição de ausente, sujeitando-se a sanção disciplinar, e caso não retorne no prazo de oito dias, configura-se a deserção. Na segunda, o militar encontra-se ausente legalmente e deixa de apresentar-se após o término do prazo de afastamento autorizado. Na terceira, o militar não se apresenta no momento da partida ou do deslocamento da unidade onde serve. Ao deixar de apresentar-se após o afastamento autorizado, o militar passa à condição de ausente, consuma-se a deserção. Entretanto, se o militar não se apresenta no momento da partida ou deslocamento da unidade em que serve, consuma-se a deserção de imediato.

A primeira modalidade a que se refere Lobão é a deserção propriamente dita. Tratase do tipo básico que é a ausência ilegal do militar, onde este deveria estar a serviço, por mais de oito dias, prevista no artigo 187 do COM[3].

A segunda modalidade é prevista nos incisos do artigo 188 do COM, são os denominados "casos assimilados" ou ainda "formas assemelhadas", que trazem quatro hipóteses de incidência criminal.

Por fim, a terceira hipótese, está prevista no artigo 190 do COM, essa modalidade se difere das demais, pois não persiste o prazo de graça ${ }^{[4]}$, ou seja, sua consumação é imediata. O Código a denomina de "deserção especial", porém a doutrina atribuiu o nome de "deserção imediata", a julgar pela sua forma de consumação[5].

Exibidas as modalidades, cumpre salientar que com base nessa classificação que se desenvolverão os próximos itens da pesquisa, havendo referências específicas no 
tocante a cada modalidade, quando se fizer necessário, com o intuito de tornar o trabalho mais didático em cada ponto da investigação[6].

\subsection{OBJETIVIDADE JURÍDICA}

A finalidade dos dispositivos referentes ao crime de deserção é tutelar a devida prestação do serviço militar, prejudicada pelo militar que se mantém ilegalmente ausente.

Para tanto Lobão (1999, p. 229) concebe o entendimento de que o objeto da tutela penal no crime de deserção é:

[...] o serviço militar diante da conduta do militar que o abandona, apesar do dever legal de cumpri-lo até sua desvinculação na forma estabelecida em lei. A norma penal tem, ainda, em vista o interesse da instituição castrense em contar com o efetivo estabelecido em lei, o que não acontece, se ficar a critério do militar ausentar-se da corporação, em desacordo com preceito legal que trata da cessação do serviço militar.

Neves e Streifinger (2005, p. 253) consideram que:

No tipo penal em estudo tutela-se o serviço militar afetado pelo fato de o agente não estar presente. Protege-se, ademais, o dever militar, o comprometimento, a vinculação do homem aos valores éticos e funcionais da caserna e de sua profissão.

Loureiro Neto (1992, p. 156) também vai além e acrescenta:

O civil pode ingressar nas forças armadas, seja voluntariamente ou quando convocado. Em qualquer hipótese, assume um compromisso de honra e uma obrigação de direito público, de levar a termo sua missão até o fim do prazo legal a que fique sujeito.

Nesse contexto podemos considerar que dentre as obrigações contraídas pelos militares, uma das mais relevantes é apresentar-se regularmente, quando determinado, na unidade militar ou no lugar onde se encontra lotado, mantendo assim a devida observação aos valores éticos da carreira militar. 
Por fim, podemos concluir a partir das características legais que não cabe ao juízo do próprio militar a decisão de ausentar-se da corporação, sem justo motivo, mas sim de acordo com o critério estabelecido pelo comando competente.

Dessa forma o legislador resguardou os interesses das instituições militares, que podem dispor de seu efetivo, íntegro e capaz, objetivando o cumprimento de missões de garantia da lei, da soberania, do patrimônio e da integridade territorial nacional, dentre outros atributos constitucionais.

\subsection{SUJEITOS DO DELITO}

O sujeito ativo do crime de deserção é exclusivamente o militar, seja federal ou estadual, devidamente matriculado e incorporado em qualquer Organização Militar da Ativa, bem como em certos Órgãos de Formação da Reserva.

Segundo Lobão (1999, p. 229 - 230) o agente do delito de deserção é: "Somente o militar legalmente incorporado às Forças Armadas, à Polícia Militar e ao Corpo de Bombeiros Militar, por se tratar, como ficou dito, de crime propriamente militar."

Por militar podemos conceituar: como a pessoa que em tempo de paz ou de guerra, seja incorporada às Forças Armadas, segundo o artigo 22 do CPM, in verbis:

Pessoa considerada militar:

Art. 22. É considerada militar, para efeito da aplicação dêste Código, qualquer pessoa que, em tempo de paz ou de guerra, seja incorporada às fôrças armadas, para nelas servir em pôsto, graduação, ou sujeição à disciplina militar.

A partir do artigo 22 do CPM compreendemos por meio de qual procedimento a pessoa adquire o status de militar, isto é, o ato de incorporação à força militar. Deste ponto de vista, Neves e Straifinger (2014, p. 930) afirmam que:

$\mathrm{RC}: 96606$

Disponível em: https://www.nucleodoconhecimento.com.br/administracao/constituicao-federal 
O marco que habilita a pessoa a cometer deserção, portanto, é o ato de incorporação à Força Militar, ou ato equiparado, que inicie o vínculo de ligação com a Instituição Militar, ainda que de formação de militares da reserva.

Nesse contexto podemos assinalar que a incorporação e a matrícula são os atos, administrativos, de inclusão do convocado ou voluntário em uma Organização Militar. Tais atos estão estabelecidos na Lei no 4.375 de 17 de agosto de 1964 - Lei do Serviço Militar, nos artigos 20 e 22[7].

Então para que o sujeito possa ser reputado como desertor, além de praticar um dos verbos nucleares dos tipos penais elencados, por exemplo, nos artigos 187, 188 e 190 do COM este deve estar legalmente incorporado por uma Organização Militar da Ativa ou Órgão de Formação da Reserva, ostentando assim o status de militar[8].

Por fim, o sujeito passivo, titular do bem jurídico violado, é a própria Instituição Militar de que é membro o desertor.

\subsection{ELEMENTOS OBJETIVOS DO TIPO}

Lobão (1999, p. 232) define de forma categórica os elementos objetivos do crime de deserção:

Elementos Objetivos - O núcleo do tipo é ausentar-se, é afastar-se, sem autorização, por mais de oito dias, da unidade em que serve ou do local onde deve permanecer, em serviço.

A descrição típica não se refere somente ao militar que se encontra no interior do estabelecimento militar, em serviço ou não, ou do local onde deve permanecer e dele se ausenta, não mais retornando. Alcança igualmente, aquele que se encontra afastado momentaneamente e não mais retorna à unidade. Por exemplo, o militar que se recolhe à sua residência no fim de semana, que está de folga fora da unidade, e não retorna.

A expressão lugar onde deve permanecer não se restringe, necessariamente, a estabelecimento castrense: pode ser um lugarejo, uma pequena cidade, um posto ao lado do rio, do mar, aeroporto de

RC: 96606

Disponível em: https://www.nucleodoconhecimento.com.br/administracao/constituicao-federal 
pequeno porte, delegacia da capitania dos portos, etc., o que não excluiu a vinculação do militar a determinada unidade castrense [...]

Consuma-se a deserção com a ausência do militar por mais de oito dias, sem licença do superior hierárquico competente para conceder a autorização.

Podemos, pois, afirmar em outras palavras que, a conduta nuclear do tipo penal é "ausentar-se", no sentido de abandonar, debandar, afastar-se da "unidade em que serve ou do local" que deva estar por força de obrigação conexa ao serviço militar. A descrição típica alcança também o militar momentaneamente afastado e que não retorna à unidade em que serve, ou seja, não se resume apenas ao militar que se encontra nas dependências do quartel e desse local se ausenta.

Tal ausência deve ser por arbítrio do próprio militar, isto é, necessariamente "sem licença" concedida pela autoridade competente, pois caso houver a devida licença não há crime, pois não ocorreu o injusto, a lesão ao bem jurídico tutelado pelo tipo penal.

Da mesma forma que ausência deve se proceder sem licença outro requisito é lapso temporal de "mais de oito dias" que o militar deve ficar afastado para a configuração do crime, caso contrário irá incorrer apenas em transgressão disciplinar - ausência.

Isto posto, devemos observar a existência da modalidade da deserção instantânea (artigo 190, CPM), em que o núcleo da conduta incriminada é "deixar o militar de apresentar-se no momento da partida" do navio ou aeronave, de que é tripulante, ou da partida ou do deslocamento da unidade ou força em que serve. Dessa maneira percebe-se que esta modalidade não guarda o período de graça que assiste ao agente da primeira (artigo 187, CPM) e segunda (artigo 188, CPM), modalidade da deserção. 


\subsection{ELEMENTOS SUBJETIVOS DO TIPO}

O tipo penal sob análise comporta apenas a prática dolosa. O elemento subjetivo é o dolo, isto é, a vontade livre e consciente do militar em ausentar-se nos termos do tipo penal, praticando assim o crime de deserção.

Nessa mesma concepção Neves e Streifinger (2005, p. 953) apontam que o elemento subjetivo da deserção "só admite o dolo, a intenção, a vontade livre e consciente de furtar-se ao serviço militar, faltando com o respectivo dever".

Em outras palavras, Lobão (1999, p. 235) conclui que o elemento subjetivo do crime de deserção "é a vontade livre e consciente do militar de ausentar-se além do prazo previsto em lei, da unidade onde serve ou do local onde deve permanecer na prestação de serviço militar".

Em suma, podemos concluir que não há a possibilidade de se praticar esse ilícito na forma culposa, estando excluído o dolo no caso do agente que acredita deveras que sua ausência é legal, quando na verdade tal ausência encontra algum vício, como no caso do militar liberado temporariamente do serviço, por uma autoridade militar incompetente, circunstância desconhecida pelo liberado.

\subsection{CONSUMAÇÃO E TENTATIVA}

Acerca da consumação da deserção, propriamente dita (artigo 187 do CPM), é necessário examinar dois elementos constitutivos do delito: a) A ausência do militar, sem licença, da unidade em que serve ou do lugar em que deveria permanecer; e b) Que esse lapso temporal que o militar se faz ausente seja superior a 8 (oito) dias.

Dessa maneira antes de decorrido o prazo de 8 (oito) dias não há a configuração da deserção, mas sim a ausência ${ }^{[9]}$ do militar (transgressão disciplinar punível administrativamente $\left.{ }^{[10]}\right)$. Esse lapso de tempo é intitulado pela doutrina como "prazo de graça".

RC: 96606

Disponível em: https://www.nucleodoconhecimento.com.br/administracao/constituicao-federal 
O prazo de graça é contado a partir da constatação da ausência do militar que deveria estar presente. Tal ausência deve ser injustificada, constituindo o elemento normativo descrito no tipo legal que abrange não só o militar que se furta de estar presente no interior do quartel junto a sua unidade, mas também de qualquer outro lugar que deva estar a serviço, como, por exemplo, uma posição militar estabelecida em uma montanha.

A contagem do prazo de graça para a consumação da deserção ${ }^{[1]}$ observa a regra do artigo 451, $\S 1^{\circ}$ do Código de Processo Penal Militar - CPPM, in verbis:

Art. 451. Consumado o crime de deserção, nos casos previsto na lei penal militar, o comandante da unidade, ou autoridade correspondente, ou ainda autoridade superior, fará lavrar o respectivo termo, imediatamente, que poderá ser impresso ou datilografado, sendo por ele assinado e por duas testemunhas idôneas, além do militar incumbido da lavratura.

$\S 1^{\circ} \mathrm{A}$ contagem dos dias de ausência, para efeito da lavratura do termo de deserção, iniciar-se-á a zero hora do dia seguinte àquele em que for verificada a falta injustificada do militar.

$\S 2^{\circ}$ No caso de deserção especial, prevista no art. 190 do Código Penal Militar, a lavratura do termo será, também, imediata.

A partir da leitura da disposição legal em destaque contata-se que devemos excluir da contagem o dia em que se verifica a ausência injustificada do militar, e começar contar a partir da zero hora do dia seguinte, prosseguindo a contagem até à zero hora do dia em que se completam oito dias, ou seja, o delito somente se consuma quando completar mais de oito dias inteiros (192 horas).

Costa (2004, p. 123) ilustra o desenvolvimento cronológico da contagem do prazo de graça até consumar-se a deserção, junto às etapas administrativas a serem realizadas pela Autoridade de Polícia Judiciária Militar:

- Tabela no 1: Progressão cronológica para a consumação da deserção. 


\begin{tabular}{|c|c|c|c|c|c|c|c|c|c|}
\hline \multicolumn{10}{|c|}{ CONTAGEM DA AUSÊNCIA ILEGAL ATÉ CONSUMAR-SE A DESERÇÃO } \\
\hline $\begin{array}{l}\text { Data } \\
10\end{array}$ & $\begin{array}{l}\text { Data } \\
11 \\
00 \mathrm{~h}\end{array}$ & $\begin{array}{l}\text { Data } \\
12 \\
00 \mathrm{~h}\end{array}$ & $\begin{array}{l}\text { Data } \\
13\end{array}$ & $\begin{array}{l}\text { Dat } \\
\text { a } \\
14\end{array}$ & $\begin{array}{l}\text { Dat } \\
\mathbf{a} \\
15\end{array}$ & $\begin{array}{l}\text { Dat } \\
\mathbf{a} \\
16\end{array}$ & $\begin{array}{l}\text { Dat } \\
\text { a } \\
17\end{array}$ & $\begin{array}{l}\text { Dat } \\
\mathbf{a} \\
18\end{array}$ & $\begin{array}{l}\text { Data } \\
19 \\
00 \mathrm{~h}\end{array}$ \\
\hline $\begin{array}{l}\text { Início } \\
\text { do } \\
\text { serviç } \\
\text { o do } \\
\text { militar } \\
\text { faltos } \\
\text { o }\end{array}$ & $\begin{array}{l}\text { Início da } \\
\text { contage } \\
\text { m da } \\
\text { ausência } \\
\text { ilegal }\end{array}$ & $\begin{array}{l}\text { Elaboraç } \\
\text { ão da } \\
\text { parte de } \\
\text { ausência } \\
\text { ilegal }\end{array}$ & $\begin{array}{l}\text { Elaboraç } \\
\text { ão dos } \\
\text { inventário } \\
\mathrm{s} \text { da } \\
\text { Fazenda } \\
\text { Pública e } \\
\text { bens } \\
\text { particular } \\
\text { es do } \\
\text { ausente }\end{array}$ & $\begin{array}{l}\text { Diligê } \\
\text { despa } \\
\text { para }\end{array}$ & $\begin{array}{l}\text { Ências } \\
\text { acho } \\
\text { encont }\end{array}$ & $\begin{array}{l}\text { cons } \\
\text { do } \\
\text { trar-se }\end{array}$ & $\begin{array}{l}\text { tatadas } \\
\text { Coman } \\
\text { o aus }\end{array}$ & $\begin{array}{l}\mathrm{s} \text { em } \\
\text { idante } \\
\text { sente }\end{array}$ & $\begin{array}{l}\text { Parte de } \\
\text { deserçãa } \\
0 \quad \text { e } \\
\text { termo } \\
\text { de } \\
\text { deserçã } \\
0\end{array}$ \\
\hline
\end{tabular}

Fonte: Costa (2004, p. 123).

Assim, com auxílio do exemplo acima, entende-se que a deserção se consuma no momento consecutivo à zero hora do nono dia de ausência. Tornando inteligível a dedução de que a contagem do prazo se dá por meio da regra processual, logo se excluindo o dies a quo e incluindo-se o dies ad quem ${ }^{[12]}$.

Agora nos voltando para a deserção especial, ou deserção instantânea (artigo 190 do CPM), essa se consuma com a ausência do sujeito ativo quando o navio ou aeronave partem ou da partida ou deslocamento da unidade ou força em que serve. Nas palavras de Neves e Streifinger (2005, p. 955), a deserção instantânea se consuma "no momento da partida da aeronave ou do deslocamento da tropa, estando ausente o militar engajado". 
No tocante as três modalidades, caso o militar venha a se apresentar, mesmo sob coação, antes de exaurido o prazo de graça, ou antes da partida do navio, a exemplo da modalidade instantânea (artigo 190, CPM), a deserção não chega a se consumar.

Quanto à tentativa, afirma sumariamente Lobão (1999, p. 235, 242 e 251) "ser juridicamente impossível" sua configuração em qualquer modalidade. No mesmo sentido Neves e Straifinger (2005, p. 955, 964 e 972) asseveram a impossibilidade da tentativa por se tratar de "crime unissubsistente". Já Nucci (2014, p. 286), além de englobar as duas lições anteriores, acrescenta que "o delito não admite tentativa porque se configura na forma omissiva que é unissubsistente", ou seja, praticada em um único ato.

\subsection{CLASSIFICAÇÃO DOUTRINÁRIA}

O crime de deserção é classificado como crime propriamente militar. Essa classificação encontra previsão legal do inciso I, 2ª parte do artigo 9º do CPM, ou seja, é um crime exclusivamente previsto no CPM, não encontrando referência no Código Penal comum além de exigir a condição de militar do agente, por ser uma infração específica e funcional dos deveres do militar. Nesse sentido Lobão (1999, p. 229) instrui que a deserção:

Classifica-se como crime militar em decorrência do disposto no inciso I, 2ª parte, do art. 9ํ do Código Penal Militar (crime não previsto na lei penal comum). Crime propriamente militar por se tratar de infração penal específica e funcional do ocupante de cargo militar.

Assim, quanto sua classificação, a deserção, é um crime propriamente militar por excelência, pois somente o militar engajado em suas funções pode configurar como sujeito ativo do delito. Dessa maneira é um dos crimes militares que melhor caracteriza as peculiaridades reunidas na legislação militar.

Nas palavras de Assis (2014, p. 557) a deserção "é crime militar por excelência, ratione materiae, ou seja: exige-se a dupla condição de militar, no fato e no agente". 
No mesmo sentido, Chaves Junior (1886, p. 65) ressalta que o crime de deserção "é crime militar por excelência, ratione materiae e ratione personae".

Já Nucci (2014, p 283) vai além à especificação do tipo penal em questão, o apontando também como um crime de mão própria, pois impossível à execução do crime, do verbo núcleo do tipo, por agente intermediário àquele que reúne as qualidades específicas exigidas pela figura típica, não se admitindo assim a coautoria, mas apenas a participação:

A deserção é não somente crime próprio, típico do militar, mas também de mão própria, que deve ser cometido pessoalmente pelo agente. Inexiste a possibilidade de se valer de interposta pessoa para tanto; pode haver, no entanto, participação, mas não coautoria.

Contudo, no tocante a natureza jurídica da deserção, há maior dificuldade em especificá-la. Segundo Assis (2014, p. 557), em relação à natureza da deserção, há uma divergência entre autores e jurisprudência, variando o entendimento se tal crime é formal, ou de mera conduta, ou ainda formal e de mera conduta ao mesmo tempo. Além de outras discussões quanto ao caráter permanente ou instantâneo do delito.

Bandeira e Gusmão no ano de 1915 já preceituavam as divergências existentes em relação à classificação do crime de deserção. Relevante então trazer à baila as palavras de ambos os autores que desenvolvem o tema com muita propriedade. (BANDEIRA; GUSMÃO, 1915)

Segundo Bandeira (1915, p. 355 - 356):

Em seu conceito doutrinário e em sua configuração legal, a deserção ora se apresenta como um delicto instantaneo, ora como um delicto continuado.

Conforme se tiver em vista um ou outro d’esses dois aspectos, variará a respectiva definição.

Sob o primeiro aspecto, a deserção é a falta de comparecimento do militar ao lugar e ao tempo em que ali se devia achar por disposição de lei ou por determinação de autoridade competente.

RC: 96606

Disponível em: https://www.nucleodoconhecimento.com.br/administracao/constituicao-federal 
E sob o segundo, é a ausencia voluntaria, prolongada e ilegal por parte do militar, do corpo a que pertence.

Os termos dessas definições justificam-se por si mesmos.

Quando se trata da deserção como um delicto instantaneo, basta a falta de comparecimento em opposição ao preceito da lei ou á ordem da autoridade competente, para integra-la seu conceito jurídico legal, desde que essa falta não seja devida a caso fortuito ou força maior.

Quando se cogita, porém, da deserção como um delicto continuado, faz-se necessária a concurrencia das tres outras condições que ficaram individuadas.

Assim, é preciso que a ausencia seja voluntaria, por isso que si ella fôr como na hypothese da exceção antecedente, o resultado de força maior ou de caso fortuito - obstaculos invenciveis de viagem, enfermidade, prisão etc - , não poderá constituir elemento de crime algum.

É mister ainda que seja prolongada para se distinguir da simples ausencia, que é uma transgressão disciplinar.

Voluntaria e prolongada, carece mais de ser illegal, porquanto si decorrer de licença ou de outra causa justificada, não poderá constituir infracção alguma penal.

Desse trecho, verificamos algumas implicações de adotarmos a classificação de crime instantâneo ou crime permanente aos aspectos e efeitos trazidos pela deserção, ou seja, não há uma definição, uma indicação, quanto à classificação mais exata, mas sim as consequências de adotarmos uma ou outra.

Por sua vez, Gusmão (1915, p. 97) nos aponta qual deve ser a classificação adotada para o crime de deserção:

A deserção é um crime continuado e não instantâneo, cujos elementos formadores e consumativo continuam sucessiva e ininterruptamente a existir, uma vez passado o prazo de graça, quando existente. $O$ facto do militar se ausentar mesmo com o animo de desertar, não constitue deserção senão após expirado o prazo, mas, uma vez expirado esse prazo, a infração continúa, n`uma serie de momentos successivos e consumativo.

RC: 96606

Disponível em: https://www.nucleodoconhecimento.com.br/administracao/constituicao-federal 
Essas conceituações ainda persistem em parte de nossa doutrina, porém com maiores incrementos. Aliás, não são incomuns tais incrementos após o decurso de mais de um século, e da mudança da legislação e do desenvolvimento doutrinário e jurisprudencial que se deram nesse período, contudo podemos constatar que os aspectos essenciais, os elementos formadores e consumativo do tipo penal, persistem inalterados.

Contemporaneamente, para maior parte da doutrina, conduzida por Célio Lobão, Jorge César de Assis, dentre outros notórios juristas, o crime de deserção é classificado como permanente, apenas cessando sua execução no momento da captura do agente ou de sua apresentação voluntária em uma unidade militar. Todavia, outros doutrinadores interpretam que, por se tratar de crime de mera conduta, quer dizer, aquele crime que não possuiu sequer previsão de ocorrência de um resultado naturalístico para a sua consumação, é certo que apenas seus efeitos é que são permanentes. Esses doutrinadores, a exemplo de Carlos Alberto Marques Soares classificam o crime de instantâneo de efeitos permanentes, afinal, basta o decurso do período de oito dias para que o crime esteja configurado (ROCHA, 2009, p. única).

Ainda no esforço de classificar a natureza do crime, Assis (2009, p. única), se utiliza da didática para tornar essa questão mais inteligível, dividindo a análise do crime "quanto à forma de ação" e "quanto ao resultado", e assim assinala:

Quanto à forma de ação (instantâneos, permanentes e instantâneos de efeitos permanentes), a deserção é um crime permanente, já que a consumação - que se deu após o oitavo dia de ausência injustificada - se prolonga no tempo. Não é crime instantâneo porque neste a consumação se dá em certo momento, não podendo mais ser cessada pelo agente [...];

Quanto ao resultado (crimes materiais, formais e de mera conduta) a deserção é crime de mera conduta (ou simples atividade) porque se configura com a ausência sem licença pura e simples do militar, além do prazo estabelecido em lei (oito dias). A deserção não pode ser formal, porque este tipo de delito traz implícito no tipo um resultado que não necessita acontecer para sua consumação.

RC: 96606

Disponível em: https://www.nucleodoconhecimento.com.br/administracao/constituicao-federal 
À vista da explanação acima, conclui-se que a deserção é crime permanente ${ }^{[13]}$ quanto à forma e de mera conduta quanto ao resultado. É permanente, pois se prolonga no tempo e somente cessa quando o agente é capturado ou se apresenta voluntariamente. É de mera conduta, pois basta a ausência sem licença do militar por mais de oito dias, sem a necessidade de um resultado externo à sua ação.

Cumpre salientar que ambas as classificações podem coexistir simultaneamente, pois cada qual integra uma espécie diferente de categoria, ou seja, a deserção é crime permanente ${ }^{[14]}$ e de mera conduta ${ }^{[15]}$.

Dessa maneira podemos determinar que dentre as classificações doutrinárias mais relevantes para o crime de deserção, ele se constitui como um crime propriamente militar por excelência; próprio e de mão própria; permanente quanto à forma e de mera conduta quanto ao resultado.

\section{O CONTROLE DE CONSTITUCIONALIDADE DE NORMAS PRÉCONSTITUCIONAIS: O FENÔMENO JURÍDICO DA RECEPÇÃO CONSTITUCIONAL}

Com o advento de uma nova Constituição há que se estabelecer como se realizar-seá o adequamento da ordem jurídica anterior a esta e, assim conforme se desenvolve este adequamento ocorrem certos fenômenos jurídicos, dentre eles a recepção.

A recepção cuida de um aspecto fenomenológico intertemporal, em que, segundo (FRIEDE, 2019, p. 21):

[...] a questão central consiste em saber quando o advento de um novo Texto Constitucional acarreta a revogação de uma norma infraconstitucional anterior. Em resposta, cumpre ter em vista que a nova ordem constitucional inaugurada sempre recebe a normatividade infraconstitucional que the é perfeitamente compatível, ainda que tal acolhimento possa ocorrer a partir de uma nova "roupagem

RC: 96606

Disponível em: https://www.nucleodoconhecimento.com.br/administracao/constituicao-federal 
normativa", originando, pois, o fenômeno da recepção, segundo o qual a legislação infraconstitucional produzida antes da instalação de uma nova Constituição será considerada acolhida pelo novel Texto Magno, continuando, por princípio de economia e segurança legislativa, a viger no âmbito próprio de sua atuação ordinária.

Dessa maneira podemos compreender a recepção como um dos fenômeno jurídico que recepciona e reconhece como válida e vigente toda a legislação infraconstitucional editada anteriormente a promulgação da atual Constituição Federal e que com ela seja compatível materialmente, ou seja, as legislações anteriores à Constituição Federal que são materialmente compatíveis com o texto constitucional permanecem em pleno vigor, uma vez que o Brasil adota o princípio da continuidade da Ordem Jurídica, aproveitando-se dos atos legislativos anteriores quando estes são compatíveis com a nova Constituição (SILVA NETO, 2009, p. 145).

Destaca-se que as normas pré-constitucionais, para serem recepcionadas, não devem contrariam materialmente a nova Constituição, isto significa que caso estas normas infraconstitucionais anteriores ao texto Constitucional as observem sob o aspecto material, contudo estejam em desacordo com as novas disposições formais, ainda sim serão recepcionadas, com a ressalva de que a edição ou ainda a criação de uma nova legislação que as substituam deverão observar as novas disposições constitucionais.

Como exemplos, pode-se apontar o Código Penal (Decreto-Lei 2.848/1940) e o Código Penal Militar (Decreto-Lei 1.001/1969), ambos infraconstitucionais, ambos anteriores a atual Constituição Federal e ambos são decretos-leis, ou seja, são uma espécie normativa que não se encontra mais prevista na Constituição, pois essa espécie normativa foi substituída em nossa Constituição Federal pelas medidas provisórias, nova espécie normativa.

Dessa maneira, ambos os Decretos-Leis citados foram recepcionados pela atual Constituição - vide inciso XXXIX, que estabelece que "não há crime sem lei anterior que o defina, nem pena sem prévia cominação legal”, princípio este expressamente presente nos referidos diplomas penais - e se encontram vigentes, mesmo que estes

RC: 96606

Disponível em: https://www.nucleodoconhecimento.com.br/administracao/constituicao-federal 
não estejam formalmente conforme o atual texto, aliás, a espécie normativa de origem desses diplomas sequer está prevista na Constituição Federal de 1988. À vista disso, os códigos foram recepcionados como leis ordinárias e, em caso de emenda a estes ou criação de novos Códigos dever-se-á necessariamente observar as normas constitucionais vigentes.

Por fim há de se salientar dois pontos relevantes a esta pesquisa, quais sejam: a) que - Supremo Tribunal Federal não admite a chamada inconstitucionalidade superveniente de ato normativo editado anteriormente a nova Constituição perante o novo Ordenamento Jurídico, pois

[...] nos casos de normas infraconstitucionais produzidas antes da nova Constituição, incompatíveis com as novas regras, não se observará qualquer situação de inconstitucionalidade, mas, apenas, como vimos, de revogação da lei anterior pela nova Constituição, por falta de recepção. (LENZA, 2017, p. 213).

Por conta deste ponto, mister notabilizar que não é possível configurar como inconstitucional o Código Penal Militar supervenientemente o que desagua no segundo ponto: b) as normas infraconstitucionais anteriores ao novo texto constitucional podem ser totalmente ou parcialmente recepcionadas (ALCÂNTARA, 2011), ou seja, o Código Penal Militar foi recepcionado pela nova Constituição, porém pode ter sido recepcionado integralmente ou parcial, por essa razão no próximo item da pesquisa analisar-se-á especificamente a recepção ou a revogação dos artigos 187 e 190 do Código Penal Militar.

\subsection{A RECEPÇÃO DOS ARTIGOS 187 E 190 DO CÓDIGO PENAL MILITAR PELA CONSTITUIÇÃO FEDERAL DE 1988}

Conforme se verificou anteriormente o Código Penal Militar fora recepcionado pela atual Constituição, porém neste item verifica-se em específico se os artigos 187 e 190 do Código Castrense foram recepcionados, tendo-se em vista que não 
necessariamente estes acompanhem o mesmo destino do Código que pode ter sido integralmente ou apenas parcialmente recepcionado.

Partindo dessa premissa e tendo-se em vista que já foram explorados os contornos legais e doutrinários dos crimes de deserção simples (artigo 187, do CPM) e deserção especial (artigo 190, do CPM), cabe no momento investigar o posicionamento jurisprudencial a este respeito.

Para tanto a investigação se debruçou sobre a jurisprudência do Supremo Tribunal Federal e por meio do sítio do Tribunal no campo de pesquisa de jurisprudência (http://portal.stf.jus.br/jurisprudencia/) lançou-se os seguintes comandos de busca: "recepção código penal militar deserção", na data de 01 de agosto de 2021. A referida busca retornou três acórdãos do Pretório Excelso, quais sejam: o Habeas Corpus 84.330, órgão julgador: Primeira Turma, de Relatoria do Ministro Marco Aurélio, com julgamento na data de 29/06/2004 e publicação em 27/08/2004 que aqui será nomeado de "Acórdão A"; o Habeas Corpus 113.857, órgão julgador: Pleno do Tribunal, Relatoria do Ministro Dias Toffoli, com julgamento na data de 05/12/2013 e publicação em 30/10/2014, que aqui será nomeado de "Acórdão B" e por último o Habeas Corpus 119.567, órgão julgador: Pleno do Tribunal, Relatoria do Ministro Dias Toffoli, com julgamento na data de 22/05/2014 e publicação em 30/10/2014, que aqui será nomeado de "Acórdão C".

$\mathrm{Na}$ análise dos acórdãos buscou-se verificar se menções sobre a aplicação dos artigos 187 e 190 do Código Penal Militar e, portanto, identificar se os mesmos foram recepcionados pela Constituição Federal de 1988 e se há argumentos contrários e/ou favoráveis sobre essa questão.

Sobre o Acórdão A, foi possível observar que este se pronuncia especificamente sobre a recepção pela Constituição Federal do artigo 187 do Código Penal Militar, valendo destaque os seguintes trechos do venerável acórdão: 
CRIME MILITAR - DESERÇÃO - PRISÃO - ARTIGOS 187 DO CÓDIGO PENAL MILITAR E 456 A 459 DO CÓDIGO DE PROCESSO PENAL MILITAR - RECEPĈ̃̃O PELA CARTA DE 1988. A PRISÃO NO CRIME DE DESERCÃO - ARTIGO 187 DO CÓDIGO PENAL MILITAR - MOSTRA-SE HARMÔNICA COM O DISPOSTO NO INCISO LXI DO ARTIGO 5 DA CONSTITUICÃO FEDERAL.

$[\ldots]$

A deserção o é, valendo notar que permanece enquanto não se apresente o militar. A razão de ser do preceito está na disciplina a ser mantida, dispondo o artigo 457 do Código de Processo Penal Militar que o desertor sem estabilidade que se apresente ou for capturado deve ser submetido à inspeção de saúde e, considerado apto para o serviço militar, será reincluído. Em suma, não procede o que articulado pela Defensoria Pública no tocante à ausência de recepção da legislação especial de regência do caso. Indefiro a ordem. (grifos nossos) (BRASIL, 2004)

Conclui-se, portanto que o Acórdão $A$ adentrou no tocante a recepção ou não recepção do artigo 187 do Código Penal Militar, uma vez que expressamente apontou que o referido artigo se mostra harmônico com a disposição presente no artigo $5^{\circ}$, inciso LXI, da Constituição Federal de 1988, bem como que não procedem os argumentos articulados pela Defensoria Pública no tocante à ausência de recepção da legislação especial de regência do caso analisado. Não houve voto ou teses e argumentos em contrário e o artigo 190 do Código Penal Militar não foi mencionado no acórdão.

Por sua vez, no Acórdão B, não foi possível constatar pronunciamentos expressos e diretos sobre a recepção ou não recepção dos artigos 187 e 190 do CPM, presente no caso concreto e no corpo do acórdão o artigo 187, mas mais uma vez ausente o artigo 190. Por fim esta decisão trouxe somente a reflexão sobre a recepção ou não de outros dispositivos, sendo estes o artigo 88, inciso II, alínea "a", do Código Penal Militar, e do artigo 617, inciso II, alínea "a", do Código de Processo Penal Militar, mas estes artigos não tratam sobre nenhuma espécie do crime de deserção, mas sim sobre a suspensão condicional da pena dos crimes militares em tempo de paz. 
Vele destacar que no tocante a recepção ou não pela atual Constituição dos dispositivos do artigo 88, do CPM e do 617, do CPPM não houve unanimidade sobre a questão ao contrário, os votos da Corte Suprema se dividiram igualmente, ocorrendo empate. Contudo, "verificado o empate na votação o Tribunal concedeu a ordem, com base no art. 146, parágrafo único do RISTF, sem pronunciamento quanto à recepção ou não do art. 88, II, alínea "a”, do Código Penal Militar, e do art. 617, II, alínea "a”, do Código de Processo Penal Militar" (BRASIL, 2014).

Por último o Acórdão $C$, se revela semelhante ao Acórdão $B$, uma vez que o caso concreto e a questão de mérito tratado por ambos são idênticos, ou seja, este também não analisa frontalmente e especificamente a recepção ou não dos artigos 187 e 190, do CPM, mas sim a recepção ou não dos artigos 88, inciso II, alínea "a", do CPM, e do art. 617, II, alínea "a”, do CPPM, contudo este acórdão taxativamente prescreve que estes últimos dispositivos também se encontram recepcionados pela Constituição vigente (BRASIL, 2014) (porém também vale a ressalva de que não fora unânime), conforme os trechos em destaque:

EMENTA: DIREITO PENAL MILITAR. VEDAÇÃO DO SURSIS. CRIME DE DESERÇÃO. COMPATIBILIDADE COM A CONSTITUIÇÃO FEDERAL

1. A jurisprudência do Supremo Tribunal Federal inclina-se pela constitucionalidade do tratamento processual penal mais gravoso aos crimes submetidos à justiça militar, em virtude da hierarquia e da disciplina próprias das Forças Armadas. Nesse sentido, há o precedente que cuida da suspensão condicional do processo

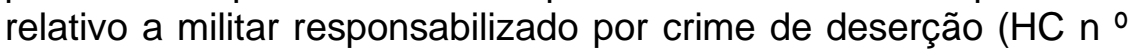
99.743, Pleno, Rel. Min. Luiz Fux).

2. Com efeito, no próprio texto constitucional, há discrímen no regime de disciplina das instituições militares. Desse modo, como princípio de hermenêutica, somente se deveria declarar um preceito normativo conflitante com a Lei Maior se o conflito fosse evidente. Ou seja, deve-se preservar o afastamento da suspensão condicional da pena por ser opção política normativa. 3. Em consequência, entende-se como recepcionadas pela Constituição as normas previstas na alínea "a" do inciso II do artigo 88 do Código Penal Militar e na alínea "a" do inciso II do artigo 617 do Código de 
Processo Penal Militar. 4. Denegação da ordem de habeas corpus. (grifos nossos). (BRASIL, 2014)

Dessa maneira, temos que por meio da jurisprudência do Supremo Tribunal Federal o crime de deserção insculpido no artigo 187 e seguintes do Código Penal Militar possui compatibilidade material com a Constituição Federal de 1988.

Assim conclui-se que o Código Penal Militar fora recepcionado, assim como os crimes de deserção positivados no artigo 187 e 190 do Código Castrense, mesmo este último não tendo sido mencionado nos acórdãos. Contudo, importa destaque aos resultados da pesquisa jurisprudencial no sentido de que não há unanimidade da Suprema Corte quanto a recepção de todos os artigos do Código Penal Militar, portanto poderá ocorrer com uma eventual mudança no entendimento do Tribunal o reconhecimento de uma não recepção de determinados dispositivos do Código Castrense e então estaríamos diante de uma recepção parcial do referido Diploma, contudo o que temos como o resultado da presente pesquisa é que os artigos 187 e 190 do referido Código foram recepcionados pela atual Constituição e encontram-se plenamente vigentes.

\section{CONCLUSÃO}

O objetivo da presente pesquisa foi revisar e analisar o crime de deserção e duas de suas modalidades previstas no Código Penal Militar brasileiro (Decreto-Lei oㅡ 1001, de 21 de outubro de 1969), quais sejam: o crime de deserção simples (artigo 187) e o crime de deserção especial (art. 190). Verificaram-se os contornos legais e doutrinários que envolvem o crime de deserção e suas modalidades de maneira analítica e sistemática, bem como verificar se tais dispositivos legais foram recepcionados pela atual Constituição Federal.

Concluída a pesquisa sobre o crime de deserção e suas modalidades verificamos com maior amplitude a sua importância para o ordenamento jurídico militar, pois versa sobre a tutela do empenho das instituições militares em dispor de seu efetivo íntegro e capaz, no objetivo de cumprir com suas missões de garantia do cumprimento da lei, 
a preservação da soberania nacional, do patrimônio público e da integridade territorial nacional, dentre outras atribuições constitucionais.

Sobreveio o conhecimento de que a principal diferença entre a deserção simples, prevista no art. 187 do CPM, e a deserção especial, também chamada de instantânea, prevista no art. 190 do CPM, reside nos elementos constitutivos do delito, mais especificamente no momento da consumação do crime.

Para apurar-se a consumação da deserção simples é necessário examinar os seguintes elementos constitutivos do delito: a) A ausência do militar, sem licença, da unidade em que serve ou do lugar em que deveria permanecer; e b) Que esse lapso temporal que o militar se faz ausente seja superior a 8 (oito) dias. Antes de decorrido o prazo de 8 (oito) dias não há a configuração da deserção, mas sim a ausência do militar (transgressão disciplinar punível administrativamente). Esse lapso de tempo é intitulado pela doutrina como "prazo de graça".

O prazo de graça, que totaliza 192 (cento e noventa e duas) horas, é contado a partir da constatação da ausência do militar que deveria estar presente. Tal ausência deve ser injustificada, constituindo o elemento normativo descrito no tipo penal. Assim entende-se que a deserção simples se consuma no momento consecutivo à zero hora do nono dia de ausência.

A deserção especial, por sua vez, contém um elemento constitutivo diverso da deserção simples para se examinar sua consumação. Nessa está presente o elemento da ausência do agente, sem licença, da unidade em que serve ou do lugar em que deveria permanecer. Porém para se consumar a deserção especial não existe o lapso temporal de 8 (oito) dias, basta que o militar não se apresente quando, por exemplo, o navio zarpe do porto, a unidade terrestre entre em marcha ou a decolagem da aeronave. Por esse motivo a doutrina nomeia essa modalidade de deserção como "deserção instantânea", pois não há prazo de graça. 
Dessa maneira, conclui-se que a deserção instantânea é consumada quando a unidade em que o agente serve se põe em deslocamento e o militar que deveria se fazer presente não o faz.

Verificou-se também que o Código Penal Militar contempla três modalidades de crime de deserção, sendo elas: a simples (art. 187) e a especial (art. 190), ambas já analisadas, e pôr fim a deserção denominada pela lei de "casos assimilados" ou ainda de "formas assemelhadas", pela doutrina. Nessa modalidade o militar encontra-se ausente legalmente e deixa de apresentar-se após o término do prazo de afastamento autorizado. Por exemplo: um militar ausenta-se devidamente licenciado por autoridade competente para gozar um período de férias de 30 (trinta) dias. Passados os trinta dias o militar tem o dever de retornar para a unidade em que serve ou do lugar em que deve permanecer. Na hipótese de não retornar no dia subsequente ao fim das férias e ultrapassado mais o prazo de graça, 8 (oito) dias, sem a reapresentação ou captura do militar ausente estará consumada a deserção por caso assimilado.

Em conclusão no tocante à análise dos referidos crimes, cabe salientar que, mesmo sem a pretensão de esgotar o assunto, os objetivos iniciais da pesquisa foram alcançados conforme demonstrado acima. Contudo duas consideráveis diferenças restaram fora da análise e do debate, pois não fora previamente cogitada, mas que atraíram a atenção: a diferença na severidade da pena imposta em cada modalidade do crime de deserção. Ao se verificar o texto legal constata-se uma progressão de pena conforme o decorrer do tempo ausente do agente delituoso no caso da deserção especial (art. 190, §§ 1ำ $2^{\circ}$ e $2^{\circ}-A$, do CPM), além de não cominar pena nos casos de captura do infrator nessa modalidade e nem haver previsão legal da sanção penal para os casos em que o há apresentação espontânea após o décimo dia o que gera uma fragilidade no tipo penal em análise, pois pelo princípio da legalidade não se poderia punir o infrator uma vez que não há pena prevista em lei e; não fora analisada se há diferença na aplicação de tais dispositivos do Diploma Castrense em relação ao âmbito institucional dos agentes, não se diferenciando os militares federais (membros 
das Forças Armadas) e os militares estaduais (membros das Polícias Militares e Corpos de Bombeiros).

Diante da consideração exposta recomenda-se a análise futura da questão e a consulta da seguinte obra: "Deserção Especial e a Possibilidade de Interpretação Extensiva com Base no Preceito Secundário", de autoria de Cícero Robson Coimbra Neves.

Por sua vez no tocante ao recepcionamento ou não dos referidos dispositivos legais pela atual Constituição Federal, temos que os artigos 187 e 190 do Código Penal Militar foram recepcionados pela Constituição Federal de 1988, uma vez que são materialmente compatíveis com o texto constitucional e com os princípios estabelecidos por ela e que orientam o Ordenamento Jurídico.

Por fim, diante de todo o exposto é possível estimar a complexidade e a relevância da interpretação das normas e fenômenos intertemporais do Direito, principalmente, no tocante a renovação do Ordenamento Jurídico pela promulgação de um novo texto constitucional, como foi a Constituição Federal de 1988. Tendo o presente artigo se proposto tão somente a concentrar a verificação da interpretação sobre um dos referidos fenômenos intertemporais, qual seja a recepção constitucional, sobre o Código Penal Militar e, especificamente sobre a modalidade simples e especial do crime de deserção.

\section{REFERÊNCIAS}

ALCÂNTARA, Guilherme. Fenômenos do Poder Constituinte: breve estudo dos fenômenos da recepção, desconstitucionalização e repristinação, atos jurídicos que estão estreitamente ligados ao Poder Constituinte e, como consequência, à matéria constitucional. 11 jul. 2011. Disponível em: < 
https://www.direitonet.com.br/artigos/exibir/6378/Fenomenos-do-PoderConstituinte>. Acesso em 26 de jul. 2021.

ASSIS, Jorge César de. Comentários ao Código Penal Militar: comentários, doutrina, jurisprudência dos tribunais militares e tribunais superiores e jurisprudência em tempo de guerra. 8ª̣ ed. Curitiba: Juruá, 2014.

Um exame minucioso sobre a natureza do crime de deserção. Conteúdo Jurídico, Brasília-DF: 19 jan. $2009 . \quad$ Disponível em:<http://www.conteudojuridico.com.br/?artigos\&ver=2.22830\&seo=1>. Acesso em: 02 de jun. de 2017.

BANDEIRA, Esmeraldino Olímpio Torres. Curso de Direito Penal Militar. Rio de Janeiro: Livraria Francisco Alves. 1915.

BRASIL. Decreto-Lei 1.001, de 21 de outubro de 1969. Código Penal Militar. Disponível em: < http://www.planalto.gov.br/ccivil_03/decreto-lei/del1001.htm >. Acesso em: 05 jul. 2021.

BRASIL. Decreto-Lei 1.002, de 21 de outubro de 1969. Código de Processo Penal Militar. Disponível em: < http://www.planalto.gov.br/ccivil_03/decreto-lei/Del1002.htm >. Acesso em: 05 jul. 2021.

BRASIL. Supremo Tribunal Federal. Habeas Corpus 84.330-1 Rio de Janeiro.

Relator: Ministro Marco Aurélio. Julgado em 29/06/2004; Publicado em 27/08/2004.

BRASIL. Supremo Tribunal Federal. Habeas Corpus 113.857 Amazonas. Relator: Ministro Dias Toffoli. Julgado em 05/12/2013; Publicado em 30/10/2014.

BRASIL. Supremo Tribunal Federal. Habeas Corpus 119.567. Relator: Ministro Dias Toffoli. Julgado em 22/05/2014; Publicado em 30/10/2014. 
COSTA, Alexandre Henrique da. Manual Prático dos atos de polícia judiciária militar. São Paulo: Suprema Cultura, 2004.

CHAVES JUNIOR, Edgard de Brito. Direito Penal e Processo Penal Militar. Rio de Janeiro: Forense, 1986.

FRIEDE, Reis. Recepção, Repristinação, Desconstitucionalização e Mutação Constitucional. Revista Juscontemporânea do TRF2. Rio de Janeiro, 2019, p. 17 a 29, out. 2019 / jan. 2020. Disponível em:

$<$ http://revistaauditorium.jrj.jus.br/index.php/revistajuscontemporanea/article/view/26 2>. Acesso em: 28 jul. 2021.

GUSMÃO, Crysolito de. Direito Penal Militar. Rio de Janeiro: Jacintho Ribeiro dos Santos Editor, 1915.

LENZA, Pedro. Direito Constitucional Esquematizado. $21^{1}$ ed. São Paulo: Saraiva, 2017.

LOBÃO, Célio. Direito Penal Militar. Brasília: Brasília Jurídica, 1999.

NETO, José da Silva Loureiro. Direito Penal Militar. São Paulo: Atlas, 1992.

NEVES, Cícero Robson Coimbra. Deserção Especial e a Possibilidade de Interpretação Extensiva com Base no Preceito Secundário. Disponível em: < http://www.jusmilitaris.com.br > Acesso em 08 de jul. 2021.

NEVES, Cícero Robson Coimbra; STREIFINGER, Marcello. Apontamentos de Direito Penal Militar: parte especial. São Paulo: Saraiva, 2005.

Manual de Direito Penal Militar. 4ª ed. São Paulo: Saraiva, 2014.

NUCCl, Guilherme de Souza. Código Penal Militar Comentado. 2ª ed. Rio de Janeiro: Forense. 2014.

RC: 96606

Disponível em: https://www.nucleodoconhecimento.com.br/administracao/constituicao-federal 
ROCHA, Eduardo Biserra. Apontamentos sobre o crime de deserção. Revista Jus Navigandi, Teresina, ano 14, n. 2214, 24 jul. 2009. Disponível em:

<http:/jus.com.br/artigos/13213>. Acesso em: 08 de jul. de 2021.

SILVA NETO, Manoel Jorge e. Curso de Direito Constitucional. 4. ed. Rio de Janeiro: Lumen Juris, 2009.

SIQUEIRA, Helena Guerreiro Silva Cavalcanti. Apontamentos sobre o crime de deserção. Revista Direito Militar, Associação dos Magistrados das Justiças Militares Estaduais - AMAJME, Florianópolis, n. 88, p. 23 -26, março/abril, 2011.

\section{APÊNDICE - REFERÊNCIA DE NOTA DE RODAPÉ}

3. Art. 187. Ausentar-se o militar, sem licença, da unidade em que serve, ou do lugar em que deve permanecer, por mais de oito dias: Pena - detenção, de seis meses a dois anos; se oficial, a pena é agravada.

4. O crime de deserção se consuma após transcorrer oito dias da constatação de ausência do militar, salvo na deserção instantânea (artigo 190 do CPM). Este intervalo de oito dias em que o militar ausentasse, sem licença, é chamado prazo de graça. Antes de o agente consumar esse prazo, ele não é dado como desertor, mas como ausente, isto é, para a configuração do crime de deserção é necessário que o agente extrapole o período de graça, estando ausente por um intervalo superior a oito dias.

5. Art. 190. Deixar o militar de apresentar-se no momento da partida do navio ou aeronave, de que é tripulante, ou do deslocamento da unidade ou força em que serve: Pena - detenção, até três meses, se após a partida ou deslocamento se apresentar, dentro de vinte e quatro horas, à autoridade militar do lugar, ou, na falta desta, à autoridade policial, para ser comunicada a apresentação ao comando militar competente. 
- 1 Se a apresentação se der dentro de prazo superior a vinte e quatro horas e não excedente a cinco dias: Pena - detenção, de dois a oito meses.

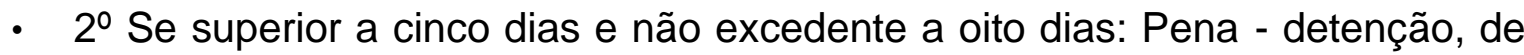
três meses a um ano.

- $2^{\circ}-$ A. Se superior a oito dias: Pena - detenção, de seis meses a dois anos.

- 30 A pena é aumentada de um terço, se se tratar de sargento, subtenente ou suboficial, e de metade, se oficial.

6. Essas três modalidades não esgotam todas as previsões do delito de deserção no CPM, mas como assinalado anteriormente, essa escolha foi feita na tentativa de melhor constatar as variáveis da pesquisa e isolar seu objeto principal, qual seja, a comparação entre a deserção simples e a deserção especial.

7. Art. 20. Incorporação é o ato de inclusão do convocado ou voluntário em uma Organização Militar da Ativa das Forças Armadas.

Art. 22. Matrícula é o ato de admissão do convocado ou voluntário em qualquer Escola, Centro, Curso de Formação de Militar da Ativa, ou Órgão de Formação de Reserva.

8. Devemos destacar o seguinte aspecto relevante: se um cidadão civil é convocado à incorporação e não se apresenta dentro do prazo estabelecido, este incorre no crime de Insubmissão (artigo 183 do CPM); porém, caso esse mesmo cidadão venha a ser oficialmente incorporado, seja em uma organização Militar da Ativa ou Órgão de Formação da reserva, adquirindo assim o status de militar e, por exemplo, pratique a conduta descrita no artigo 187, caput do CPM, será considerado desertor. Sendo o status de militar um condição de procedimentalidade da ação penal.

9. A definição legal de ausente é dada pelo artigo 89 da lei no $6.880 / 80$ - Estatuto dos Militares - "É considerado ausente o militar que, por mais de 24 (vinte quatro) horas consecutivas: I- deixar de comparecer à sua organização sem comunicar qualquer 
motivo de impedimento; e II- ausentar-se, sem licença, da organização militar onde serve ou do local onde deve permanecer".

10. Segundo Jorge Cesar de Assis "para se chegar até o crime de deserção o militar terá que, necessariamente passar pela transgressão disciplinar da ausência. Diríamos, guardadas as devidas proporções que tanto a transgressão disciplinar quanto o crime militar são violações do mesmo dever militar, ou seja, que a deserção é uma infração (ou violação) progressiva, onde o militar evolui da simples transgressão da disciplina para o cometimento do crime, sem solução de continuidade". ASSIS, Jorge Cesar de. Prazo para a consumação da deserção: afinal, são quantos dias?. Conteúdo Jurídico, Brasília-DF: 06 mar. 2010. Disponível em: <http://www.conteudojuridico.com.br/?artigos\&ver=2.26168\&seo=1>. Acesso em: 29 de mai. 2017.

11. Entre a deserção propriamente dita (artigo 187 do CPM) e seus casos assimilados (artigo 188 do CPM) não há diferenças em relação ao prazo de graça, ambos os crimes se consomem após 8 (oito) dias de ausência injustificada. Exceto a modalidade especial ou instantânea (artigo 190 do CPM).

12. Assim a lavratura do termo de deserção (documento essencial para o processo de deserção), é regrada pelo prazo especificado no $\S 1^{\circ}$ do artigo 451 do CPPM, e não conforme a regra, de direito material, estabelecida no artigo 16 do CPM, in verbis: "Art. 16. No cômputo dos prazos inclui-se o dia do começo. Contam-se os dias, os meses e os anos pelo calendário comum".

13. Se o crime é permanente, seu agente, no caso o desertor, se encontra em contínua situação de flagrante delito, podendo ser capturado a qualquer tempo (o que autoriza a prisão do desertor é a lavratura do competente Termo de Deserção, artigo 454 do Código Processual Penal Militar, sendo necessário o mandado judicial apenas nos casos em que a autoridade competente tiver que proceder a prisão dentro do domicílio do desertor). 
14. Não podendo ser classificado ao mesmo tempo como crime instantâneo ou instantâneo de efeitos permanentes.

15. Não podendo comportar ao mesmo tempo a classificação de crime material ou formal, apenas de mera conduta.

Enviado: Agosto, 2021.

Aprovado: Setembro, 2021. 